reapproximated with a tenaculum before rigid fixation on either side of the midline. The retrosternal structures were protected with a malleable retractor. The remaining defects at the areas of the osteotomies were packed with the bone from the initial portion of the procedure. The two halves of the sternum were then reapproximated with standard sternal wires, which were placed around the sternal plates (Figure $2, B)$. The patient's postoperative course was unremarkable, with resolution of the deformity, and she was discharged home in 4 days.

\section{DISCUSSION}

Most traumatic sternal fractures are treated nonoperatively, and only patients with fractures that are displaced or cause severe pain are operated on in the acute setting. This strategy was established by Richardson and colleagues ${ }^{3}$ with their report on 11 patients. Their management involved sternal fixation with wires, obviating sternal resection. In addition, they commented that dense scar present after a waiting period of just 1 week made the operation difficult. Bertin and associates ${ }^{4}$ described treatment of chronic sternal fractures with nonunion in 3 patients. Only 1 had a history of previous fracture. All were first seen with debilitating pain. The technique of Bertin and associates ${ }^{4}$ involved excision of the fracture site, rigid internal fixation with parallel plates, and bone grafting of the residual defect. Gallo and coworkers ${ }^{5}$ reported 1 case of a traumatic sternal fracture with chronic nonunion, again treated with plate fixation and iliac crest bone grafting. Our case, although similar, differs in that the patient's sternum had healed in a severely angulated position, causing debilitating pain and deformity. This case also differs in that iliac bone grafting was not necessary, so we were able to use our wedge osteotomy specimens as the graft. Because of the severe angulation of the healed sternum, an attempt at resection and repair without median sternotomy would bear unnecessary risk. We therefore used the technique of surgical débridement and rigid internal fixation with titanium plates with autologous bone grafting.

Chronic sternal fracture associated with debilitating pain and sternal deformity is an uncommon problem. It should be approached with the concepts of débridement of abnormal bone and rigid internal fixation. The use of large titanium plates and screws provides rigid fixation, allowing healing of the sternum.

\section{References}

1. Fokin AA, Robicsek F. Acquired deformities of the anterior chest wall. Thorac Cardiovasc Surg. 2006;54:57-61.

2. Ravitch M, Steichen F. Atlas of general thoracic surgery. Philadelphia: Saunders; 1988.

3. Richardson JD, Grover FL, Trinkle JK. Early operative management of isolated sternal fractures. J Trauma. 1975;15:156-8.

4. Bertin KC, Rice RS, Doty DB, Jones KW. Repair of transverse sternal nonunions using metal plates and autogenous bone graft. Ann Thorac Surg. 2002;73:1661-2.

5. Gallo DR, Lett ED, Conner WC. Surgical repair of a chronic traumatic sternal fracture. Ann Thorac Surg. 2006;81:726-8.

\title{
Pumpless extracorporeal gas exchange aiding central airway surgery
}

\author{
Thorsten Walles, MD, ${ }^{\mathrm{a}}$ Volker Steger, MD, ${ }^{\mathrm{a}}$ Holger Wurst, MD, ${ }^{\mathrm{b}}$ Klaus-Dieter Schmidt, MD, ${ }^{\mathrm{b}}$ and Godehard Friedel, MD, ${ }^{\mathrm{a}}$ \\ Gerlingen, Germany
}

In the setting of tracheobronchial resection and reconstruction, skilled coordination between surgeons and anesthesiologists is mandatory. However, tubing lines traversing the operating field, splashing liquids caused by tracheal gas flows, and thoracic excursions caused by artificial ventilation complicate the surgical procedure, especially when microsurgical techniques are applied. ${ }^{1}$ Therefore, during

From the Departments of Thoracic Surgery ${ }^{\mathrm{a}}$ and Anesthesiology, ${ }^{\mathrm{b}}$ Schillerhöhe Hospital, Gerlingen, Germany.

Received for publication Nov 4, 2007; accepted for publication Dec 24, 2007.

Address for reprints: Thorsten Walles, MD, Department of Thoracic Surgery, Schillerhöhe Hospital, Solitudestrasse 18, D-70839 Gerlingen, Germany (E-mail: twalles@ yahoo.com).

J Thorac Cardiovasc Surg 2008;136:1372-4

$0022-5223 / \$ 34.00$

Copyright $@ 2008$ by The American Association for Thoracic Surgery doi:10.1016/j.jtcvs.2007.12.092 surgery pulmonary ventilation may be replaced temporarily by alternative oxygenation techniques that are limited by the rise in arterial partial pressure of carbon dioxide $\left(\mathrm{PaCO}_{2}\right)^{2}$ The development of a new generation of low-resistance oxygenator membranes paved the way for pumpless extracorporeal lung assist (pECLA) devices that operate without expensive equipment and the expenses for trained staff. ${ }^{3}$ Because of our clinical pECLA experience in patients with acute lung failure, we applied this technology intraoperatively to afford the reconstruction of an extensive tracheoesophageal defect.

\section{CLINICAL SUMMARY}

A 63-year-old man was admitted for defect closure of an extensive esophagotracheal defect that had developed 

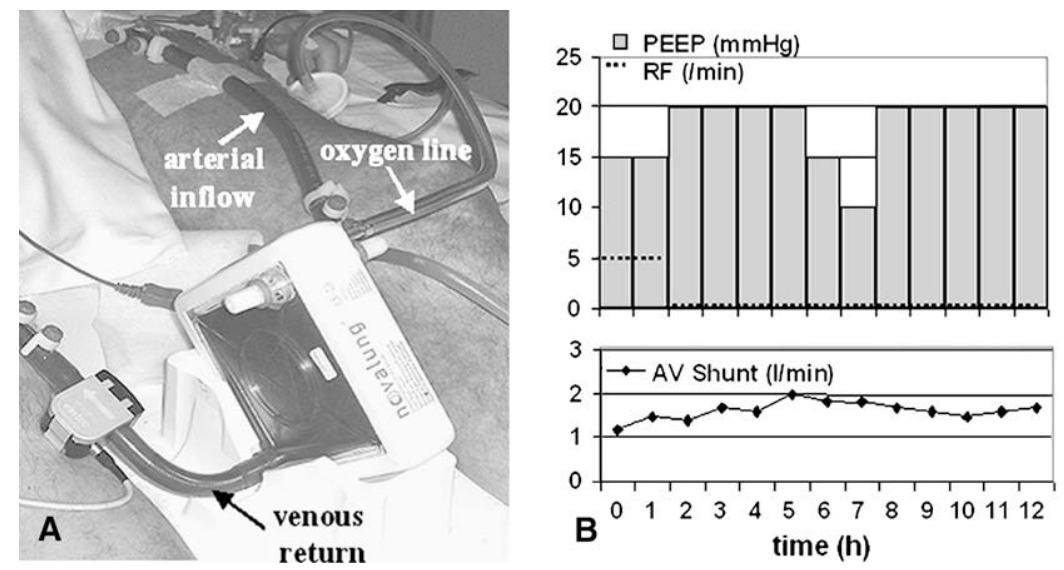

FIGURE 1. Intraoperative implementation of the pumpless extracorporeal lung assist (pECLA) device. A, System configuration showing the major system components: vascular access by percutaneous femoral arterial and venous cannulation (arrows) and the membrane oxygenator. A continuous oxygen flow (12 $\mathrm{L} / \mathrm{min}$ ) is administered via a connected oxygen line (arrow) to remove total body $\mathrm{CO}_{2}$ production and to oxygenate the circulating blood. $\mathrm{B}$, Intraoperative ventilation parameters (upper chart) displaying positive end expiratory pressure (PEEP) management and artificial respiration frequency $(R F)$ and $\mathrm{pECLA}$ arteriovenous shunt volume ( $A V$ shunt) (lower chart) during intraoperative bypass.

following laryngectomy and suprajugular tracheostomy by a bioartificial vascularized esophagotracheal patch. ${ }^{4}$ The patient was unable to eat or drink and suffered from chronic microaspiration. On chest radiograph, both lower lobes showed infiltrative signs suggestive of aspiration pneumonitis. Chest computed tomography and bronchoscopy showed a $6 \times 2-\mathrm{cm}$ defect of the anterior esophageal wall extending into the posterior wall of the remaining trachea. Lung function tests and blood gases, however, showed normal pulmonary function. To provide optimal surgical exposure for defect closure and mircroanastomosis of the bioartificial implant to the cervical vasculature on one hand, and to ensure reliable patient ventilation and oxygenation on the other, the Interventional Lung assist device (iLA) (Novalung, Hechingen, Germany) was applied during surgery. Following induction of general anesthesia, iLA was implemented by insertion of 2 low-resistance cannulas into the right femoral artery and the contralateral femoral vein and 5000 international units heparin was administered. For esophagotracheal reconstruction, ventilation was ceased, maintaining an increased positive end-expiratory airway pressure (Figure 1, A) using a blocked, small-diameter tracheal tube advanced to the tracheal carina while the accumulating $\mathrm{CO}_{2}$ was removed by the iLA. At the end of surgery, regular ventilation was implemented; the iLA was removed electively on the following day, and the patient was allowed to wake up.

\section{RESULTS}

Lung ventilation was ceased for 10 hours. pECLA implementation resulted in an average arteriovenous shunt volume of $1.6 \pm 0.2 \mathrm{~L} / \mathrm{min}$ (Figure 1, B) with no significant decrease of the systemic arterial function (Table 1). Throughout surgery, sufficient patient oxygenation was provided and almost all metabolically produced $\mathrm{CO}_{2}$ was removed (Table 1). The unhindered operation field afforded the microanastomosis of 4 vessels using an operation microscope (Optio Pentero, Carl Zeiss Meditec, Jena, Germany). Following termination of anesthesia and iLA removal, neurologic function was normal, and there were no device-associated complications, such as bleeding from the insertion sites or limb ischemia.

TABLE 1. Resulting respiratory parameters during intraoperative pECLA bypass

\begin{tabular}{lccccccccccc}
\hline & \multicolumn{10}{c}{ pECLA bypass time (h) } \\
\cline { 2 - 11 } & $\mathbf{0}$ & $\mathbf{1}$ & $\mathbf{2}$ & $\mathbf{3}$ & $\mathbf{4}$ & $\mathbf{5}$ & $\mathbf{6}$ & $\mathbf{7}$ & $\mathbf{8}$ & $\mathbf{1 0}$ & $\mathbf{1 2}$ \\
\hline $\mathrm{pH}$ & 7.57 & 7.55 & 7.53 & 7.50 & 7.50 & 7.47 & 7.52 & 7.47 & 7.42 & 7.50 & 7.45 \\
$\mathrm{pCO}_{2}(\mathrm{~mm} \mathrm{Hg})$ & 26.3 & 27.1 & 29.2 & 31 & 29.6 & 30.8 & 27.5 & 29.1 & 28.8 & 30.2 & 32.8 \\
$\mathrm{pO}_{2}(\mathrm{~mm} \mathrm{Hg})$ & 87.4 & 167.7 & 478 & 386 & 224 & 475 & 424 & 363 & 296 & 335 & 293 \\
$\mathrm{HCO}_{3}^{-}(\mathrm{mmol} / \mathrm{L})$ & 24.1 & 23.6 & 24.0 & 23.7 & 23.0 & 22.1 & 22.1 & 20.9 & 20.5 & 23.3 & 22.5 \\
$\mathrm{BE}(\mathrm{mmol} / \mathrm{L})$ & 1.9 & 1.2 & 1.3 & 0.7 & 0.1 & -1.1 & -0.5 & -2.2 & -5.3 & 0.4 & -1.0 \\
$\mathrm{~S}_{\mathrm{O} 2}(\%)$ & 97.5 & 99.2 & 100 & 100 & 99.6 & 99.8 & 100 & 99.3 & 99.8 & 100 & 99.3 \\
\hline
\end{tabular}

Time points matching Figure 1 with " 0 " indicating abandonment of regular artificial ventilation and intraoperative implementation of pECLA. $p E C L A$, Pumpless extracorporeal lung assist; $B E$, base excess. 


\section{DISCUSSION}

The concept of pumpless lung assistance depends on a new generation of oxygenator systems with a low transmembrane pressure gradient to remove total body $\mathrm{CO}_{2}$ production and are designed to operate without the help of an external pump. Simply connected to the patient's systemic circulation, they receive only part of the cardiac output for extracorporeal gas exchange. Therefore, stable hemodynamics and the absence of severe peripheral occlusive disease are prerequisites for pECLA implementation. Whereas ample experience has been published applying pECLA as an auxiliary ventilation device in patients with ventilation-refractory lung failure and hypercapnia, only limited data are published applying pECLA as a substitute for ventilation in patients with a normal lung function. ${ }^{5}$ In the presented case, pECLA was applied to ease tracheoesophageal reconstruction by avoiding interferences by the management and handling of the anesthesia tubing.

The applied iLA device is easy to implement and to monitor, so it can be operated by the anesthetist collateral to the usual anesthesiologic equipment. Therefore, this technology is also applicable in small thoracic surgery units that do not have available trained perfusionists. Additionally, no costs are incurred for acquisition and servicing of pump heads.
It has been shown clinically and experimentally that the short iLA tubing lines hardly induce any systemic inflammatory reaction, which may makes these systems applicable for the intraoperative support of tumor patients. ${ }^{5}$

This is, to our best knowledge, the first successful intraoperative application of a pECLA device. Although anecdotal, this encouraging experience unlocks the door for the clinical application of pECLA devices in surgical patients who need exceptionally delicate intraoperative airway management or who need intrathoracic surgery following extensive pulmonary resection where therapeutic interventions are limited.

\section{References}

1. Alfille P. Anesthesia for tracheal surgery. In: Grillo HC, ed. Surgery of the trachea and bronchi Chapter 18. 1st ed. Hamilton, London: BC Decker Inc; 2004: 453-70.

2. Hess DR, Gillette MA. Tracheal gas insufflation and related techniques to introduce gas flow into the trachea. Respir Care. 2001;46:119-29.

3. Matheis G. New technologies for respiratory assist. Perfusion. 2003;18: 245-51.

4. Macchiarini P, Walles T, Biancosino C, Mertsching H. First human transplantation of a bioengineered airway tissue. J Thorac Cardiovasc Surg. 2004;128: 638-41.

5. Walles T. Clinical experience with the iLA membrane ventilator pumpless extracorporeal lung-assist device. Expert Rev Med Devices. 2007;4:297-305.

\section{Giant left atrial thrombus with mechanical compromise of the mitral valve}

Andres Beiras-Fernandez, MD, ${ }^{\mathrm{a}}$ Patrick Moehnle, MD, ${ }^{\mathrm{b}}$ Ingo Kaczmarek, MD, ${ }^{\mathrm{a}}$ Florian Weis, MD, ${ }^{\mathrm{b}}$ Bruno Reichart, MD, ${ }^{\mathrm{a}}$ and Calin Vicol, MD, ${ }^{a}$ Munich, Germany

Free-floating giant thrombus is a rare and severe finding observed occasionally in patients with atrial fibrillation and concomitant mitral valve disease. ${ }^{1}$ Herein, we report the case of a 76-year-old woman with acute heart failure and lung edema resulting from a giant left atrial thrombus that mechanically compromised the mitral valve.

\footnotetext{
From the Departments of Cardiac Surgery ${ }^{\mathrm{a}}$ and Anesthesiology, ${ }^{\mathrm{b}}$ Grosshadern University Hospital, Munich, Germany.

Received for publication Nov 4, 2007; revisions received Dec 20, 2007; accepted for publication Dec 22, 2007.

Address for reprints: Andres Beiras-Fernandez, MD, Department of Cardiac Surgery, Grosshadern University Hospital, Marchioninistrasse 15, 81377 Munich, Germany (E-mail: abeiras@med.uni-muenchen.de).

J Thorac Cardiovasc Surg 2008;136:1374-6

$0022-5223 / \$ 34.00$

Copyright (c) 2008 by The American Association for Thoracic Surgery doi:10.1016/j.jtcvs.2007.12.072
}

\section{CLINICAL SUMMARY}

A 76-year-old woman with a record of mitral stenosis was referred to our department because of acute respiratory insufficiency and cardiogenic shock. The electrocardiogram showed atrial fibrillation. Chest radiograph showed massive pulmonary edema and an enlarged heart silhouette. Multislice computed heart tomography showed the presence of intracavitary masses in the enlarged left atrium and confirmed the absence of coronary disease (Figure 1, $A$ and $B$ ).

Transesophageal echocardiography showed a dilated left atrium $(95 \times 80 \mathrm{~mm})$ and severe mitral valve insufficiency, as well as confirming the presence of two thrombi. The larger one was an $80 \times 65-\mathrm{mm}$ free-floating ball thrombus in the middle of left atrium (Figure 2, A) and the second 